\title{
Criando a realidade através da narrativa: análise comparada das notícias sobre migração veiculadas por UN News e CNN
}

\author{
Creating reality through narrative: a comparative \\ analysis of migration news from UN News and CNN
}

DOI: $10.21530 /$ ci.v15n1.2020.935

Natália Diniz Schwether ${ }^{1}$

Gabriela Santos Nascimento ${ }^{2}$

\section{Resumo}

Este artigo compara notícias veiculadas pela UN News, portal da ONU, e pelo jornal eletrônico $\mathrm{CNN}^{3}$. Emprega-se a técnica de análise de conteúdo, com o intuito de identificar diferentes abordagens sobre a temática das migrações, restritas ao segundo semestre de 2018. A hipótese de pesquisa é que, em geral, a UN News adota em suas abordagens uma postura mais humanitária que a $\mathrm{CNN}$, em consonância com os valores expressos desde a fundação da Organização. A perspectiva teórica construtivista fornece suporte à pesquisa, ao considerar que a realidade é uma construção social influenciada por diversos atores (entre eles a mídia), assim como a sociologia da comunicação, a qual retrata a construção da notícia como um processo influenciado por uma série de práticas, procedimentos e discursos. O estudo se justifica em virtude da capacidade que as notícias possuem de influenciar a opinião pública e, até mesmo, alterar processos políticos. Dentre os principais achados destaca-se a preferência da CNN por abordar o tema com ênfase para os aspectos de segurança e econômicos, enquanto na UN News observa-se uma maior recorrência de categorias associadas aos direitos humanos.

Palavras-chave: Mídia; Migrações; Análise de Conteúdo.

1 Pós-Doutoranda em Ciência Militares na Escola de Comando e Estado Maior do Exército (ECEME). Doutora em Ciência Política na Universidade Federal de Pernambuco (UFPE), com período de estágio doutoral no Instituto Universitário de Lisboa (ISCTE-IUL). Mestre em Relações Internacionais pela Universidade Federal de Santa Catarina (UFSC), e Bacharel em Relações Internacionais pela Universidade Estadual Paulista (UNESP). ORCID: https://orcid.org/0000-0002-8022-237X; email: natidiniz@gmail.com

2 Graduada em Ciência Política pela Universidade Federal de Pernambuco (UFPE). ORCID: https://orcid.org/00000002-6442-7383; email: gabiisnascimento@hotmail.com

3 O presente trabalho foi realizado com apoio da Coordenação de Aperfeiçoamento de Pessoal de Nível Superior - Brasil (CAPES) - Código de Financiamento 001.

Artigo submetido em 08/04/2019 e aprovado em 05/11/2019. 


\begin{abstract}
This article foments a comparison between the news published by UN News, UN portal, and the electronic newspaper CNN. The technique of content analysis is used in order to identify the different approaches regarding the migration theme, restricted to the second half of 2018. The research hypothesis is that UN News adopts in its approaches, in general, a more humanitarian stance than $\mathrm{CNN}$, in line with the values expressed since the Organization's foundation. The constructivist theoretical perspective provides support for this research, considering that reality is a social construction influenced by several actors (among them the media), as well as the sociology of communication, which portrays the construction of news as a process influenced by a series of practices, procedures and speeches. The study is justified by the ability of news to influence public opinion and even change political processes. Among the main findings, the CNN's preference for addressing the issue emphasizing security and economic aspects stands out, while in UN NEWS there is a greater recurrence of categories associated with human rights.
\end{abstract}

Keywords: Media; Migration; Content Analysis.

\title{
Introdução
}

Desde sua primeira aparição nas relações internacionais no texto de Onuf (1989), seguida por sua estruturação como perspectiva teórica no trabalho de Wendt (1992), o construtivismo inovou ao apresentar a concepção de que a realidade social é construída a partir das ações e interações humanas, em constante transformação. De acordo com essa corrente, o meio internacional é composto por diversos atores, entre eles a mídia.

A mídia, ao integrar o mundo social, exerce importante papel na construção das identidades e interesses, sendo instrumento da ação política e de poder. Outrossim, ela possui múltiplas atuações, ao passo que responde aos interesses do mercado e é o principal meio de divulgação das ações estatais e de organizações internacionais (Garrido 2014). Nesse sentido, o acesso a informação e o domínio sobre os conteúdos divulgados, são, cada vez mais, valiosos recursos de poder (Nye 2004).

Cientes de que as notícias são fatos sociais categorizados (Vizeu 2003), ou seja, não correspondem a relatos puros da realidade, uma vez que nelas incorrem experiências pessoais, impressões e percepções dos jornalistas, para além das diretrizes e valores que norteiam o veículo de mídia responsável por sua divulgação 
(Pereira Jr e Rocha 2011) e, que nenhum fato possui significado antes que o mesmo seja atribuído. Os meios de comunicação são, então, responsáveis pela construção da imagem internacional dos Estados, bem como participam ativamente dos processos de tomada de decisão internos (Nogueira 2012, Jesus 2015).

Tendo em vista os achados da literatura, o presente estudo avança com o intuito de observar empiricamente a atuação da mídia como criadora da realidade e influenciadora na tomada de decisões. Para tanto, elege-se, de um lado, a Organização das Nações Unidas (ONU), a qual desde sua criação, em 1945, pela Carta das Nações Unidas, possui grande notoriedade internacional, ao tratar tanto de temas ligados à paz mundial, direitos humanos, como questões econômicas, sociais e culturais. E, de outro, nomeia-se a rede de notícias CNN, pioneira na transmissão por satélite e uma das principais importadoras de notícias para diversos jornais ao redor do globo. Embora, a rede já tenha recebido críticas por sua atuação propagandista dos interesses dos Estados Unidos, ainda assim permanece sendo um gigante conglomerado de mídia com alcance mundial (Souza 2005).

Em razão da variedade de funções atribuídas à ONU, a análise aqui proposta se restringe ao setor de Informação Pública, que corresponde à central de notícias da UN News. Igualmente, o estudo está integralmente lastreado nos princípios e valores expressos desde a fundação da Organização, a exemplo da preservação das gerações futuras das mazelas da guerra, a fé nos direitos fundamentais do homem, na igualdade de direitos de homens e mulheres e no direito internacional. De tal forma questiona-se: a UN News possui um viés mais humanitário em seu discurso, quando comparada a outros meios de informação?

Portanto, supõe-se que, ao comparar os termos utilizados na redação das notícias veiculadas pela UN News aos empregados pelos veículos de mídia tradicional, encontrar-se-á, em geral, uma abordagem mais atenta à condição e ao bem-estar do ser humano. A fim de testar a hipótese planteada, o estudo empregou a técnica de análise de conteúdo, conforme as etapas definidas por Bardin (2016).

Primeiramente, procedeu-se uma pré análise, com a leitura dos textos e a seleção do corpus. Com o intuito de tornar o estudo contemporâneo e as matérias passíveis de comparação, elegeu-se a temática das migrações e delimitou-se o período de 13 de junho (UN News) e 4 de julho (CNN) até 21 (CNN) e 30 de novembro (UN News) de 2018. Em seguida, passou-se ao tratamento dos dados e criação de códigos, o que permitiu a categorização e análise comparativa. Nuvens de palavras e a exposição de tabelas de frequência permitiram melhor visualização dos achados, dentre os quais destacam-se a preferência da CNN por abordar o 
tema com ênfase nos aspectos de segurança e econômicos, enquanto na UN News houve maior recorrência de categorias associadas aos direitos humanos, o que corrobora a expectativa inicial.

Contudo, salienta-se de antemão que esse achado não permite afirmar que as notícias veiculadas pela CNN não se preocupam com os aspectos humanitários, mas sim que os termos relacionados aos direitos humanos aparecem com menor frequência. Outrossim, frisa-se que no conjunto de matérias avaliadas estão entrevistas, as quais não necessariamente correspondem às opiniões oficiais do meio de comunicação.

Destarte, após essa introdução, o artigo segue com uma seção dedicada à revisão de literatura pertinente à área, a qual expõe os principais argumentos da corrente construtivista e a agência da mídia nas relações internacionais. Logo após, a segunda seção apresenta o objeto de estudo, a princípio com uma contextualização e evolução histórica dos meios de comunicação, para, no subtópico seguinte, definir os dois veículos selecionados para teste da hipótese. Em seguida, é apresentada a estratégia empírica, para, então, expor visualmente e criticamente os resultados e encerrar com uma breve conclusão.

\section{Revisão de Literatura}

Na concepção de Adler (1999), expoente da corrente construtivista, a ação e a interação humanas formam o mundo material enquanto simultaneamente são formadas por ele. O conhecimento normativo coletivo é o responsável por ditar o significado e a interpretação que os indivíduos têm sobre a realidade, além de servir como guia para as ações, individuais e coletivas. Tudo que hoje significa alguma coisa passou pela criação normativa do significado.

De acordo com Jackson e Sorensen (2018), tendo em vista que a realidade não é objetiva e nem externa ao observador, o sistema internacional não se forma sozinho, ele é uma construção do intelecto social. O sistema internacional, tampouco é materialmente identificável, ele é idealizado e normatizado por indivíduos específicos. Dessa forma, o mundo social não pode ser considerado separadamente da consciência humana.

Wendt (1992) foi um dos primeiros autores a propor que o sistema internacional é formado por ideias. Para esse autor, a identidade e o interesse dos agentes é mutável e não exógeno, como sugeriam as escolas tradicionais. Já a anarquia 
não é previamente estabelecida, mas faz parte de um processo que privilegia interesses específicos. Afirma, ainda, que mudança na identidade gera mudança de comportamento nos agentes e, consequentemente, na própria estrutura do sistema.

Sendo assim, a realidade não é estática e imutável, mas, sim, construída por agentes. Todos são protagonistas e as ações geram resultados, as quais movimentam o mundo. Kratochwil e Risse (1997) afirmam que o mundo é uma construção social. E, para além da ausência de precedência ontológica entre agente e estrutura, eles são simultaneamente criaturas e criadores. Embora exista um mundo material, ele só faz sentido quando lhe é atribuído valor, através de ideias e interpretações (Nogueira e Messari 2005).

Para Kratochwil e Risse (1997) uma das maiores problemáticas a ser enfrentada pelo construtivismo é a metodológica, no que concerne à correspondência entre o mundo físico e o conhecimento construído sobre ele. Os autores defendem que é comum entre os construtivistas a ideia da intersubjetividade da linguagem, o compartilhamento de discursos, significados e valores.

Nesse ponto, originam-se algumas divergências em virtude da distinta importância atribuída à virada linguística ${ }^{4}$. Construtivistas como Onuf (1989), Fierke e Jorgensen (2001) acreditam, por exemplo, que a linguagem é fundamental para a compreensão dos significados; em especial, as regras organizadoras do discurso são cruciais para a interpretação dos eventos sociais.

O construtivismo dos modernistas-linguistas, também conhecidos como "ruleoriented constructivism", resulta da combinação entre uma hermenêutica subjetiva e um interesse cognitivo por explicar e entender a realidade internacional. Esses construtivistas defendem que a compreensão das relações internacionais só pode ser feita ao se considerarem as normas e linguagens que constituem os fatos sociais (Camargo 2009, 24).

O discurso não é apenas um instrumento, mas a própria ação política. Em 1989, Kratochwil identifica no discurso as regras que nos permitem assimilar a realidade. De acordo com o autor, quando se compreendem as regras que guiam o discurso, compreendem-se também as regras que guiam a realidade, pois o

4 O movimento está centrado na relação entre linguagem e realidade. Rompe com a ideia de que a linguagem é apenas uma representação da realidade, material ou ideacional. A linguagem seria um instrumento de ação e compreensão (Gomes 2011). Nas relações internacionais Onuf é o grande precursor desse pensamento (Nogueira e Messari 2005). 
mundo é o resultado dos discursos. Assim, a linguagem é utilizada para descrever o mundo que guiará o entendimento da realidade (Nogueira e Messari 2005).

Em outras palavras, o construtivismo é um conjunto de lentes paradigmáticas através das quais observamos todas as realidades socialmente construídas - as “boas” e as “más” (Adler 1999, 224). Nesse contexto, o poder retratado seria o institucional, aquele responsável por incluir ou excluir, legitimar e autorizar (Williams 1996). Para esse tipo de poder é crucial garantir a legitimidade do ator como definidor de significados compartilhados, pois eles formam não só suas identidades, mas também seus interesses e práticas.

Sendo a realidade social construída pela imposição de significados e pela atribuição de funções para acontecimentos e materiais, a competência de definir as regras do jogo é essencial, no sentido de fazer com que os outros atores não apenas aceitem, mas concordem e se comprometam com as regras. Torná-las parte de sua auto compreensão pode ser considerada a forma mais sutil e efetiva de exercer poder (Adler e Barnett 1996, Williams 1996).

No que tange ao conceito de poder, a diversidade de definições faz com que este estudo adote a abordagem realizada por Nye (2014). Para o autor, o poder consiste na habilidade de afetar seus pares e conseguir o que se almeja. O resultado de interesse pode ser alcançado via: coerção, pagamentos ou a capacidade de atração.

Nye (1990) relata, ainda, que o poder tradicionalmente voltado para a força militar, hard power, ao longo do tempo, tem perdido seu protagonismo no cenário internacional. Mesmo sendo o recurso de autodefesa mais importante, sua utilização é cada vez mais custosa. A opinião pública melhor informada e os incrementos nas áreas de tecnologia, educação e economia, fazem com que a utilização de instrumentos como a comunicação sejam preferíveis (Nye 1990, 154-157).

Atualmente, é evidente a eficácia da mídia na disseminação de discursos. O uso dessa ferramenta permite que os Estados propaguem seus modelos culturais, que auxiliam na manutenção do status quo político, social e econômico. Afinal, “o setor de comunicação tem uma singularidade que condiciona seu funcionamento. Por um lado, serve o seu próprio mercado das comunicações e, por outro fornece o canal através do qual outros agentes podem se comunicar com o público" (Garrido 2014, 109, tradução nossa). Essa transmissão pode alcançar a arena internacional e, quando universalizados, esses modelos culturais conferem poder e importância ao Estado que os encorajar (Garrido 2014). 
Os Estados e as Organizações utilizam a mídia para disseminar modelos. Tendo como alicerce expressões culturais já existentes, como, por exemplo, a defesa dos direitos humanos, a reinvindicação de igualdade ou a defesa do meio ambiente, influenciam a opinião pública, influem e cerceiam comportamentos (Garrido 2014).

O conceito de poder, ao longo do tempo, desloca o seu foco do capital para a informação. Com o crescente número de informações disponíveis, a capacidade de obtê-las de forma exclusiva e em "primeira mão" é de suma importância. A economia baseada em informações empodera as habilidades organizacionais e flexibiliza as capacidades, indo além das matérias-primas (Nye 1990, 166).

No cenário internacional as fontes desse poder seriam a cultura, os valores e as políticas internacionais. Nesse contexto, um Estado está mais habilitado a conquistar seus interesses quando os demais países desejam seguir seu exemplo e o admiram. Nye (2014) cunhou essa via de poder como soft power. De acordo com o autor, o aumento do soft power na era da informação faz com que tenham mais poder países com múltiplos canais de comunicação, valores culturais em sintonia com os universais e credibilidade quanto às suas políticas domésticas e externas (Nye 2004). Contudo, esse poder não é monopólio estatal, tampouco sua exclusividade.

Nesse sentido, a diversificação das formas de atuação do Estado demonstra ser a estratégia mais eficaz em um cenário internacional complexo. A utilização de um único tipo de poder, seja ele hard ou soft, é ineficiente e incompleta (Pinto e Freitas 2012). Dessa maneira, agir com inteligência significa saber dosar os elementos de poder conforme as necessidades. Uma política baseada apenas na coerção pode funcionar, mas o custo normalmente é alto demais. Já, uma política que se concentra apenas em estabelecer vínculos e empatias não se sustenta diante de elementos práticos. Uma combinação das duas é, efetivamente, mais proveitosa (Bertonha 2009).

\section{O diálogo entre o Construtivismo e a Comunicação}

Em face da relevância que a comunicação possui para os Estados e organizações internacionais, esse subtópico explora com maior profundidade o processo de construção da notícia. Conforme o paradigma construtivista, presente também na comunicação, a notícia é uma narrativa construída por diversos fatores. 
Contrariando pressupostos de que a realidade é relatada por meio de um transmissor desinteressado, esse paradigma aponta para a interferência do jornalista, sendo a notícia uma construção social e o jornalista o ente responsável por criar acontecimentos sociais (Traquina 2004, Gadini 2007).

Os meios de comunicação são, antes de tudo, formados por pessoas, logo, o jornalista, ao transmitir uma notícia, possui valores e visões de mundo carregadas de vieses (Nogueira 2014) advindos de experiências e conhecimentos prévios, os quais direcionam seu olhar para fatos específicos e proporcionam determinada interpretação dos mesmos. Para Bourdieu $(1995,25)$, os jornalistas selecionam e enquadram as realidades do cotidiano em função de categorias que são reflexo de sua educação, história, cultura, entre outros. “Os jornalistas têm óculos especiais, a partir dos quais, veem certas coisas e não outras. [...] Há uma seleção e construção do que é selecionado” (Pereira Jr e Rocha 2011, 750).

Nessa mesma esteira de pensamento, Vizeu (2003) afirma que os jornalistas categorizam cada acontecimento de acordo com uma escala de importância. Nesse processo de classificação consciente dos fatos, o jornalista escolhe dentre uma abundância de acontecimentos apenas alguns para destacar, por acreditar que sejam mais noticiáveis. Dessa forma, o jornalismo utiliza, para além da experiência pessoal do jornalista, o grau de noticiabilidade para definir quais acontecimentos são importantes (Pereira Jr e Rocha 2011) ${ }^{5}$.

Logo, a construção da notícia não é apenas o relato de um fato. Isto porque o jornalista está sujeito a várias normas profissionais, sociais, linguísticas, as quais acarretam práticas, procedimentos e discursos presentes no trabalho diário, tais como: a cultura profissional, a organização do trabalho, os processos produtivos, os códigos particulares, as regras de redação, o idioma e as regras de linguagem (Vizeu 2003).

Todas essas etapas fazem com que o jornalista confira ênfase particular aos acontecimentos, o que não significa dizer que as notícias se tornem ficções ao passo que se mantém um compromisso ético com o público, que orienta a constante busca pela veracidade e a verificação das fontes e dos fatos (Pereira Jr e Rocha 2011). Entretanto, a notícia está inserida na realidade social moldada pelas ações e interesses dos atores, e os fatos escolhidos para serem noticiados, embora verídicos, carregam vieses.

5 De acordo com Charaudeau (2006, 102-103 apud Nogueira 2014, 12) a informação é selecionada em decorrência do seu potencial de atualidade, socialidade e imprevisibilidade. 
Tendo em vista que a notícia é um produto, interessa a quem a produz chamar a atenção do seu consumidor, razão pela qual uma mesma notícia pode receber distintos enfoques. O jornalista, ao escolher utilizar palavras e significados específicos, incita a sociedade de diferentes formas e causa reações as mais variadas, previstas e imprevistas.

Destarte, em uma realidade social em constante construção, nenhum fato possui total significado até que a ele seja atribuído. As notícias são, assim, importantes ferramentas para interpretação do mundo. Os fenômenos cotidianos são processos incompletos que deixam em aberto seus significados. A construção desses significados se dá na apropriação de suas relações com o mundo, de acordo com o que experienciamos dele e de como se apresentam as situações da vida cotidiana (Gadini 2007).

Mesmo que a adoção de um significado aconteça por meio de relação subjetiva entre o jornalista e os fatos, essa criação, assim como a realidade, permanece em construção. Em outras palavras, não se trata de um círculo fechado - notícia e jornalista - o leitor é, também, parte ativa desse constructo, podendo ressignificar episódios, bem como complementar aqueles atribuídos (Gadini 2007).

\section{Contextualização}

Em 1450 a veiculação de informações à população de forma sistêmica e organizada foi originalmente estabelecida com a criação da prensa, possibilitando a venda diária de jornais. Prontamente, os jornais impressos se tornaram um negócio lucrativo, dado o interesse de comerciantes em anúncios publicitários que eram, na maioria das vezes, mais rentáveis que a própria venda dos exemplares (Defleur e Bale-Rokeach 1989).

A partir da década de 1920, os meios de comunicação de massa se difundiram com as telecomunicações e a era do rádio. As transmissões eram extremamente populares devido à grande variedade de programas e, assim como o jornal, o rádio se tornou lucrativo devido a indústria publicitária (Defleur e Bale-Rokeach 1989).

O avanço da tecnologia fez com que, em 1960, a televisão se convertesse na principal fonte de informação. Já na década de 1990, foi desenvolvido o world wide web (WWW) como meio de comunicação interpessoal, sendo a sua maior revolução a possibilidade de comunicação bilateral (Monteiro 2001). 
Todos esses meios compõem, hoje, a mídia de massas ${ }^{6}$, e foram os responsáveis por universalizar o acesso a informação, atingindo a maioria da população. Por essa razão, exercem grande influência na formação de opiniões, ao passo que constroem aquilo que se acredita por realidade, além de propagarem uma identidade social.

Na atual era digital, difunde-se grande quantidade de informações instantâneas, interativas e criadas por diversos autores. O monopólio da informação foi rompido por uma rede mais integrada. Nela o expectador deixa de ser passivo para ser um agente da notícia. "Por permitir a difusão democrática da informação, a Internet cria uma nova categoria de usuário, consumidor e emissor da informação, livre para escolher o tipo de mensagem a qual quer ter acesso e que deseja ele mesmo veicular” (Rodella 2005, 43).

No entanto, desde sua idealização, a mídia sofre contradição inerente: é simultaneamente uma instituição pública e privada. O papel de guardiã do interesse público, livre propagadora de informações e promotora do debate público é paralelo aos interesses empresariais (Gomes 2007, 12 apud Fraga 2013, 33). Dado o fato de ser composta por empresas que dependem de lucro ou são concessões estatais, resta claro que a mídia não é totalmente imparcial e livre de influência (Fraga 2013).

Conquanto o surgimento da mídia privada, os Estados não perderam sua capacidade de influenciar o público. Ao contrário, eles aproveitaram o poder de indução que os meios de comunicação possuem para atuar em mais uma arena de poder, desenvolvendo relações que os favorecem. Por meio de parcerias os Estados divulgam informações que os beneficiam, interna e externamente, fazendo com que seus assuntos de interesse sejam relevantes, também, para a sociedade (Burity 2013).

Em sociedades democráticas, os meios de comunicação constituem um espaço público que permite aos cidadãos discutir e formar opinião sobre a realidade social. Uma arena de debate, na qual se permite ao leitor concordar ou discordar, e utilizar as informações disponíveis para construir seus argumentos. O jornal é um fórum no qual se escutam todas as vozes públicas, e se expressa a sua própria voz (Gadini 2007).

6 O termo 'mídia de massas' faz referência aos meios de comunicação que operam em grande escala, atingindo quase todos os membros de uma sociedade em maior ou menor grau (Mcquail 2003, 18). 
Igualmente, a mídia atua na definição das agendas governamentais como apoiadora, gerando consensos, e como entrave, diminuindo ou extinguindo opções válidas e produzindo custos. Frequentemente, ela acelera a tomada de decisão sobre temas recorrentes em suas manchetes (Jesus 2015).

A mídia é capaz de influenciar, também, as ações externas dos países, sendo importante recurso da diplomacia na disseminação de ideais e imagens sobre países ou sociedades. Nesse sentido, seu uso é oportuno quando se deseja: influenciar a opinião pública em sociedades estrangeiras; ser um meio de comunicação entre atores externos e promover a resolução de conflitos; mediar negociações internacionais, estimulando a reflexão crítica das partes em disputa (Jesus 2015).

Outrossim, uma cobertura midiática está apta a atribuir status a temas, instituições e movimentos sociais, fazendo com que suas pautas se tornem relevantes aos olhos do público. Sua cobertura pode servir como reforço positivo da autoridade e do prestígio desses grupos, como também pode deslegitimar sua causa (Jesus 2015). Isto é a mídia produz verdades e molda a opinião pública (Nogueira 2014).

O discurso midiático é, portanto, hegemônico em sua credibilidade e no poder e intensidade com que atinge os indivíduos (Araujo 2012). É inquestionável o potencial da mídia como uma ferramenta para os atores estatais e não estatais na conquista do apoio da opinião pública. Na esfera internacional a cobertura da mídia relata o cenário internacional, ao mesmo tempo em que atribui importância para os fatos, organizações e contextos.

\section{UN News}

A comunicação da ONU sofreu diversas mudanças ao longo de sua trajetória, acompanhando os avanços da tecnologia - das notas de imprensa para os jornais, a uma estação de rádio até as redes sociais e seu portal de notícias. A UN News conta, hoje, com vários jornalistas trabalhando para noticiar os acontecimentos em diversos países, línguas e tópicos de interesse (UN News 2018).

Em virtude da grande abrangência de temas abordados, que tratam, além de questões relativas à paz e direitos humanos, também questões econômicas, sociais e culturais, a instituição precisou se setorizar e criou o Departamento de Informação Pública, responsável por comunicar, informar e difundir conhecimento. 
O Departamento possui três divisões: Divisão de Comunicação Estratégica, responsável por formular a estratégia de comunicação para questões prioritárias e o lançamento de campanhas globais; Divisão de Notícias e Mídia, com a função de produção e publicação de notícias sobre o trabalho da ONU e estabelecimento de parcerias com outros meios de comunicação; Divisão de Divulgação voltada para divulgação de conhecimento, ideais e atividades exercidas pela ONU.

A Divisão de Notícias e Mídia cumpre sua tarefa por meio de uma seção de notícias e a produção de vídeos. No que tange às notícias, o principal portal utilizado é o UN News, que publica, além de manchetes atualizadas sobre acontecimentos recentes, seções temáticas como: direitos humanos, gênero, clima, entre outros. Inclui, também, discursos do Secretário Geral, serviços de alerta, RSS feeds, entrevistas e fotojornalismo. Diária e semanalmente são produzidos boletins informativos em áudio em oito idiomas, bem como realizadas transmissões ao vivo de eventos (UN News 2018).

O propósito do portal UN News é ser porta de entrada para o mundo das Nações Unidas e acesso rápido às notícias e conteúdos especiais sobre os temas em foco na Organização. A partir de uma plataforma multimídia são feitas denúncias de situações de conflito, monitoramento de missões de paz e emitidos posicionamentos a respeito da conduta dos países membros em diversas situações.

\section{Cable News Network (CNN)}

Revolucionária na comunicação, a empresa CNN foi pioneira no ramo das telecomunicações via satélite e em transmissões ao vivo. O canal alcançou reconhecimento e audiência mundial, unindo-se a várias emissoras de diferentes países. Inaugurada em 1980, em Atlanta, foi o primeiro canal de televisão a veicular exclusivamente notícias por 24 horas. É uma rede midiática global e serve como modelo para diversos canais semelhantes (Souza 2005).

A CNN fez cobertura de fatos históricos e foi a primeira emissora a noticiar os ataques às Torres Gêmeas, em de 11 de setembro de 2001, nos Estados Unidos. Sua cobertura da Guerra do Golfo foi considerada eficiente e pouco parcial. Porém, na Guerra do Iraque o viés nacionalista, até então pouco evidente, gerou críticas e acusações. O caráter propagandista da cobertura, que se dedicava quase exclusivamente a veicular imagens patriotas, foi revelado com o surgimento de canais árabes, que exibiram outra face do conflito (Souza 2005). 
A despeito das controvérsias, o canal é um dos maiores fornecedores de conteúdo da mídia mundial. A empresa, que iniciou como um canal de televisão, hoje faz parte de um dos maiores grupos de mídia, incluindo as empresas América Online, Time, Inc., New Line Cinema, Warner Bros., entre outras. Sua influência chega a diversas áreas, uma vez que, para além de produzir suas próprias notícias, fornece imagens e matérias para outros meios em todo o globo.

\section{Estratégia Empírica}

A análise de dados, sejam esses textos e/ou imagens, busca, através de uma série de procedimentos específicos, extrair um sentido àquele conjunto de informações (Creswell 2007, apud Mozzato e Grzybovski 2011). A análise de conteúdo, inicialmente criada com intuito de realizar descrições por meio do cálculo de frequências, contou com a posterior incorporação da análise qualitativa, que possibilitou compreender as características, estruturas e modelos (Câmara 2013).

Bardin (2016) define a análise de conteúdo como uma série de técnicas complementares, que buscam sistematizar e explicar o conteúdo de mensagens. A finalidade dessa abordagem é uma dedução lógica sobre a mensagem, sempre considerando o emissor, o contexto e os efeitos dela. De forma complementar, Minayo (2001) entende a análise de conteúdo como investigação do comportamento humano, com funções de verificação de hipóteses e descoberta de motivações e elementos anteriores à mensagem.

Como pontos positivos dessa técnica se destacam a clareza e a baixa ambiguidade. A aplicação do passo a passo simplifica o material e reduz a descrição de características específicas (Bauer e Gaskell 2003, apud Mozzato e Grzybovski 2011). Sua organização é cronológica e segue três etapas: pré-análise, exploração e tratamento. Detalhados na figura abaixo (Figura 1). 
Figura 1 - Etapas da Análise de Bardin

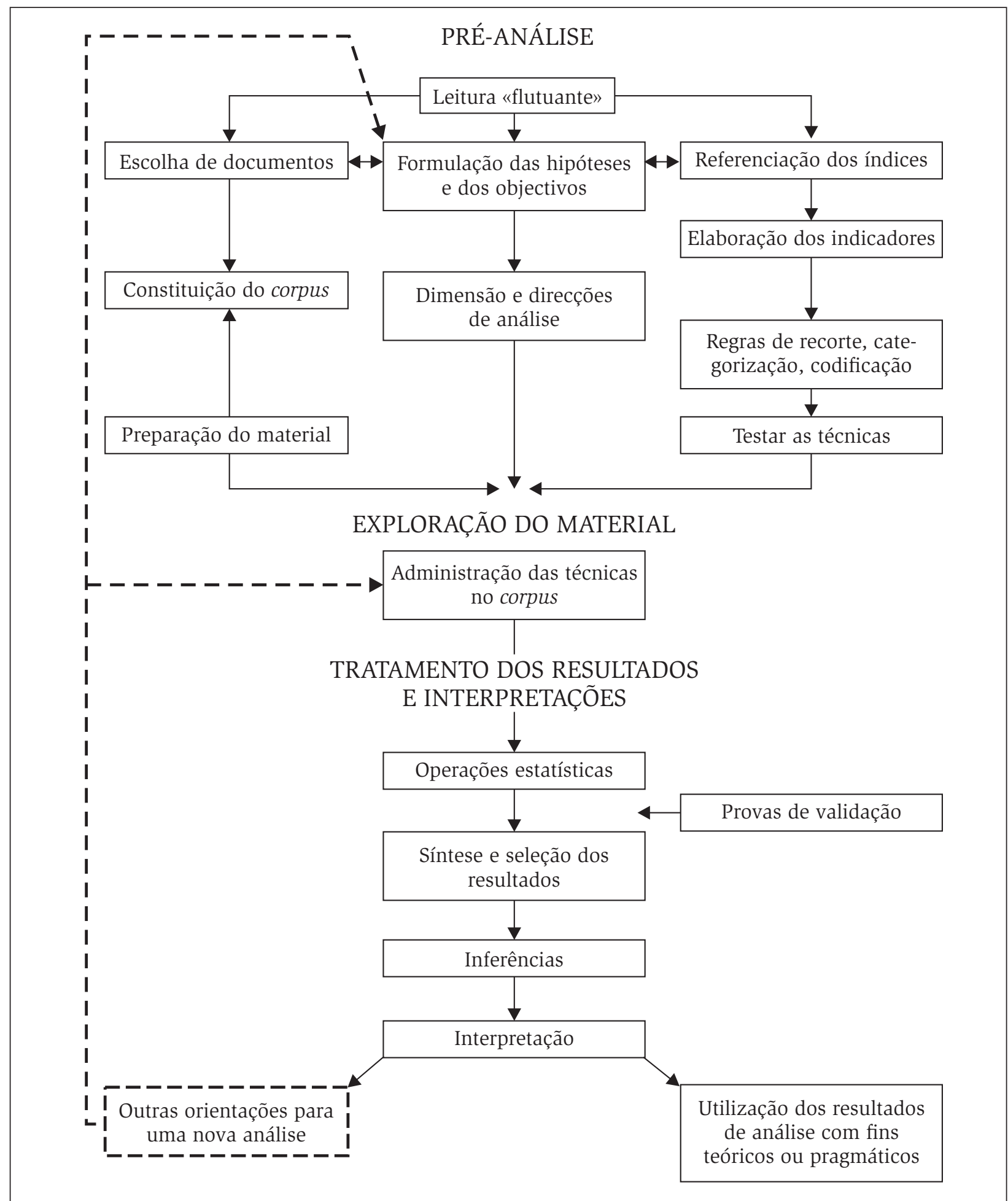

Fonte: Bardin 2016, 132.

A pré-análise é composta pela escolha dos documentos, formulação da hipótese e elaboração de indicadores. Embora não exista obrigatoriedade de sucessão entre essas etapas, elas estão interligadas e possuem o objetivo de organizar os dados. Bardin (2016) chamou de leitura flutuante o primeiro contato com os textos, o 
ganho de complexidade ocorre conforme o pesquisador avança em sua pesquisa. Uma das possibilidades para a escolha dos documentos é buscar por aqueles que contêm maior quantidade de informação sobre o objeto. Após a escolha, é necessária a constituição do corpus - conjunto de documentos a serem analisados?

No presente estudo, a leitura flutuante realizada nos portais eletrônicos dos jornais, CNN e UN News, revelou que o tema migração8 era constante, sendo uma grande fonte de material para análise. Em 2019, 271,6 milhões de pessoas foram caracterizadas como migrantes, residindo em países distintos do de seu nascimento, o que representa cerca de 3,5\% da população mundial (UN DESA 2019).

Embora existam diversos fatores que levam um indivíduo a migrar como, por exemplo, melhores condições de vida, busca por emprego, melhor educação para os filhos, reencontro de familiares, entre outros (ACNUR, 2016), eles são, recorrentemente, noticiados como mais uma fonte de concorrência por oportunidades e benefícios estatais, o que resulta em preconceitos, e motivo de ansiedade e insegurança para os atores internacionais (Bale 2008).

Dado a magnitude e expressividade do tema, passou-se a uma pesquisa em ambos os sites pelo termo "migrant". O recorte temporal foi estabelecido com o intuito de conferir contemporaneidade à pesquisa e considera a atualidade do tema. Ele corresponde ao período entre 13 de junho a 30 de novembro (UN News) e 4 de julho a 21 de novembro (CNN), ambos de 2018. O corpus gerado foi composto por 70 matérias - 35 de cada jornal.

Conforme Bardin (2016), o passo seguinte à leitura é a formulação de hipóteses e objetivos. As hipóteses podem ser formuladas por meio de técnicas sistemáticas e métodos exploratórios, processo que é auxiliado pelos textos. Ou, a partir de hipóteses pré-estabelecidas, que podem ser experimentadas por métodos de observação. No que diz respeito à elaboração de indicadores, esses podem corresponder à medida da frequência que um tema é abordado em uma mensagem. Assumindo que índices estão presentes nas mensagens, a pré análise é responsável

7 São regras: 1. Exaustividade - presença de todos os elementos, sem exceção; 2. Representatividade - a análise pode ser realizada em uma amostra se ela for representativa do universo; 3. Homogeneidade — os documentos devem ser homogêneos entre si e obedecer a critérios de escolha; 4. Pertinência - os documentos devem corresponder ao objetivo da análise (Bardin 2016).

8 Nesse estudo entendemos migração como um conceito absoluto, o qual pode ser expresso como: “o movimento de pessoas de um lugar no mundo para outro a fim de ter residência permanente ou semipermanente, geralmente atravessando uma fronteira política” (Human Migration Guide 2005 apud Costa e Reusch 2016, 277). Os distintos tipos de migração não são explorados, pois presamos pelo enfoque aos aspectos da construção da linguagem nas comunicações. Estimula-se, no entanto, que estudos futuros realizam uma reflexão mais pontual sobre cada um dos tipos e seus efeitos. 
por escolhe-los, levando em consideração as hipóteses levantadas. No presente estudo optou-se por partir de uma hipótese pré-estabelecida e experimentá-la, sendo ela: a UN NEWS possui uma postura mais humanitária em suas notícias, quando comparada a CNN.

O passo seguinte apresentado por Bardin (2016) é a exploração do material, que pode ser realizada tanto manual quanto digitalmente. É, em geral, operacionalizada através de codificações ou enumerações, e, nos casos em que a pré análise foi bem construída, essa etapa se restringe à aplicação das decisões tomadas anteriormente. Passa-se, então, para o tratamento e a interpretação dos dados, momento no qual se realizam operações que permitem a apresentação condensada da informação. Para tanto, importante etapa é a delimitação das categorias ${ }^{9}$ a serem utilizadas, a fim de comparar a frequência com que cada uma delas aparece nas notícias.

Bardin (2016) afirma que, através da categorização, o pesquisador classifica os elementos do conjunto, os diferencia e reagrupa seguindo critérios previamente definidos. O processo pode se dar através de um inventário, quando os elementos são isolados, ou de uma classificação, quando eles são reorganizados. Na classificação podem ser aplicadas duas técnicas antagônicas: na primeira, as categorias formadas e os elementos são alocados para aquela onde se encaixam melhor; a segunda classifica progressivamente os elementos e, ao final, define suas categorias.

A categorização, nesse estudo, foi desenvolvida baseada nos diversos aspectos que podem ser relatados acerca da migração, como a ligação entre economia e migração, questões de segurança e direitos humanos (United Nations 1970). Ponderou-se, ainda, a discriminação que os migrantes sofrem por parte do governo e de sua população, os quais precisam "lidar com o repúdio e com a hostilidade dos locais, além de ter menos direitos” (Human Migration Guide 2005, apud Costa e Reusch 2016, 277). Dessa maneira, foram construídas as seguintes categorias:

(1) Economia - situação dos migrantes em busca de melhores condições socioeconômicas e a economia doméstica dos países receptores. Essa categoria é formada pelos códigos: desemprego, dinheiro, emprego, oportunidade e gasto.

(2) Segurança - do país e do migrante. Formada pelos códigos: defesa, proteção, segurança, tropas e violência.

9 Categorias reúnem grupos de elementos com características partilhadas, seus critérios podem ser diversos (semânticos, sintático, léxico e expressivo). 
(3) Direitos Humanos - dignidade humana, violações dos direitos humanos e o clamor pelos mesmos. Formada pelos códigos: direitos humanos e apoio.

(4) Tratamento - acolhida dos migrantes. Seus códigos remetem a não aceitação da condição de migrante, são eles: discriminação, medo e detenção.

Isto posto, a codificação possibilita a extração do conteúdo das mensagens. Levando em consideração as categorias previamente estabelecidas, sua aplicação para todas as matérias dos jornais viabilizou a comparação entre a quantidade de vezes que cada categoria está presente nos textos do corpus, cujos resultados serão expostos à continuidade.

\section{Resultados}

A criação das categorias e a codificação possibilitaram, por meio da utilização do software Atlas.ti, a produção de três nuvens de palavras (Figuras 2, 3 e 4). A primeira contém todos os textos analisados, a segunda e a terceira foram geradas a partir dos textos da UN News e CNN, respectivamente.

\section{Figura 2 - Nuvem completa}

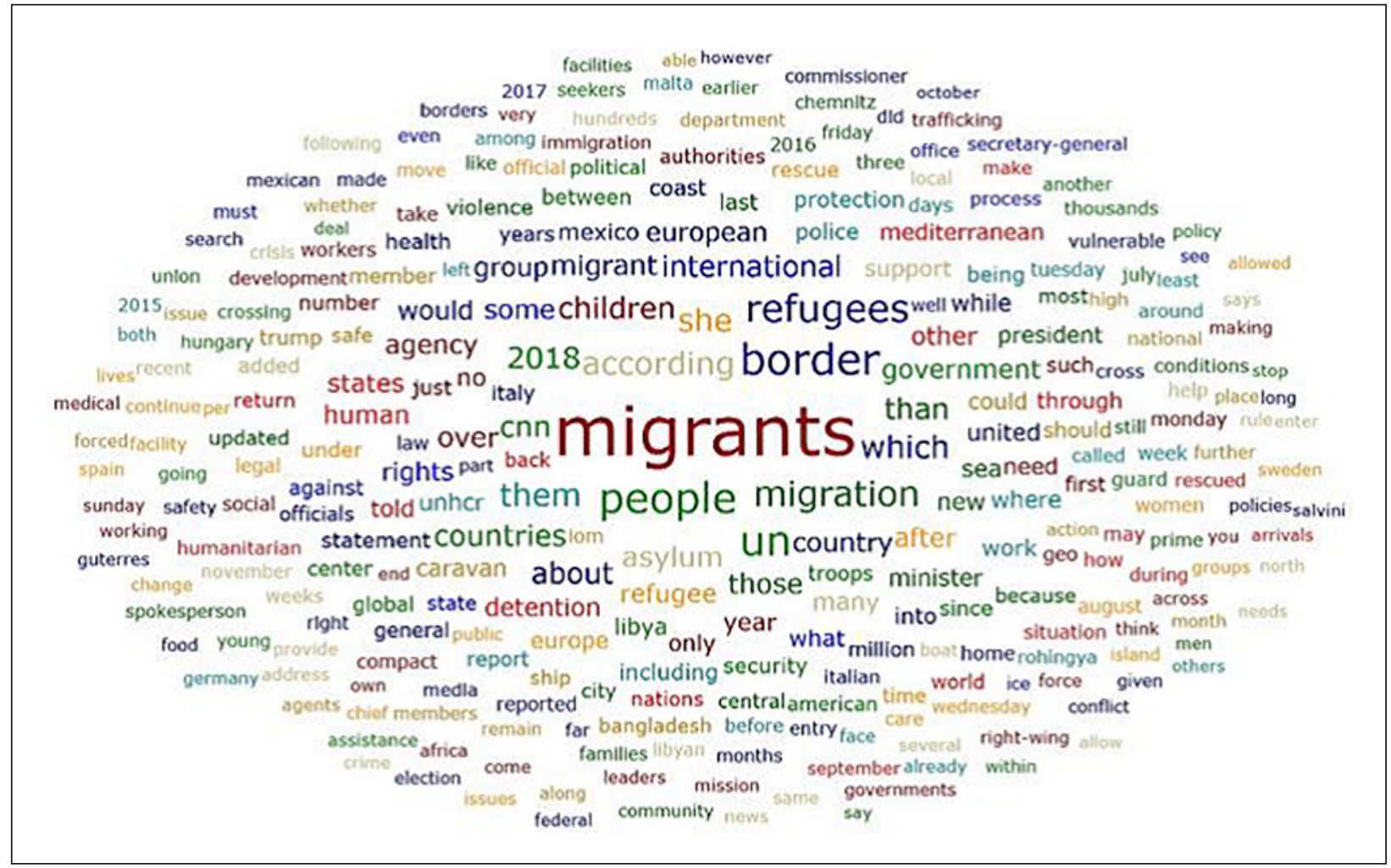

Fonte: Elaborado pelas autoras, 2018. 
Figura 3 - Nuvem UN NEWS

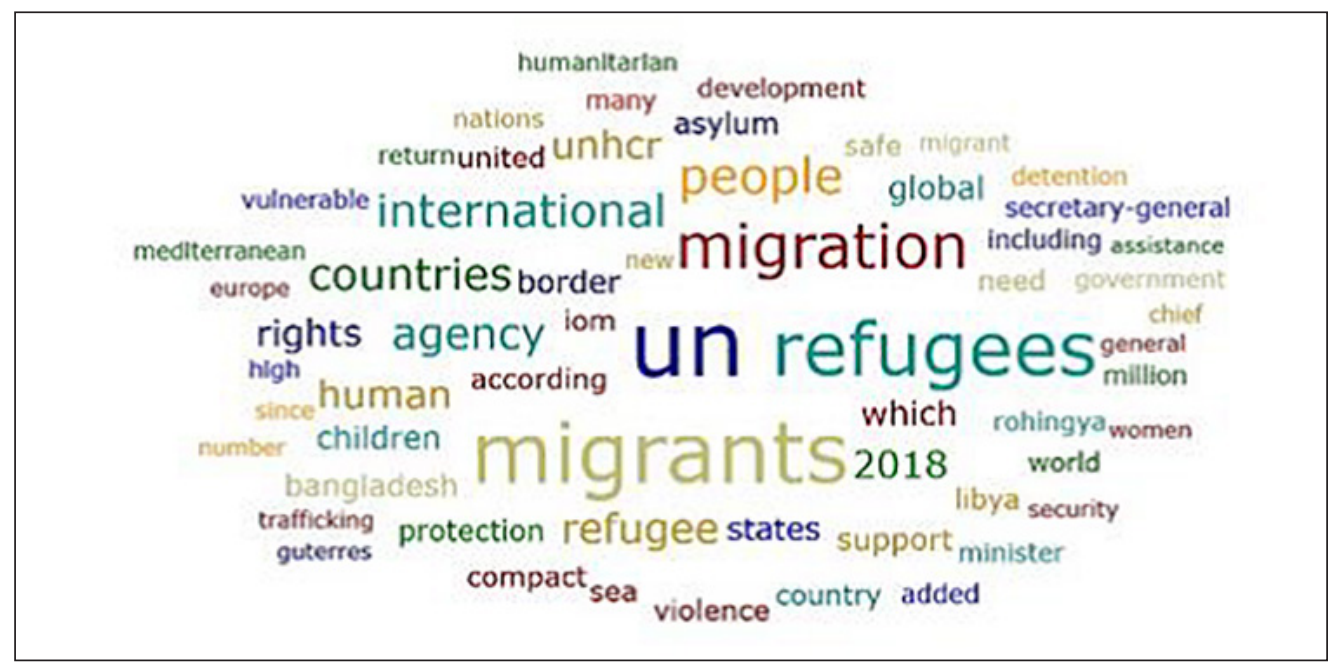

Fonte: Elaborado pelas autoras, 2018.

Figura 4 -Nuvem CNN

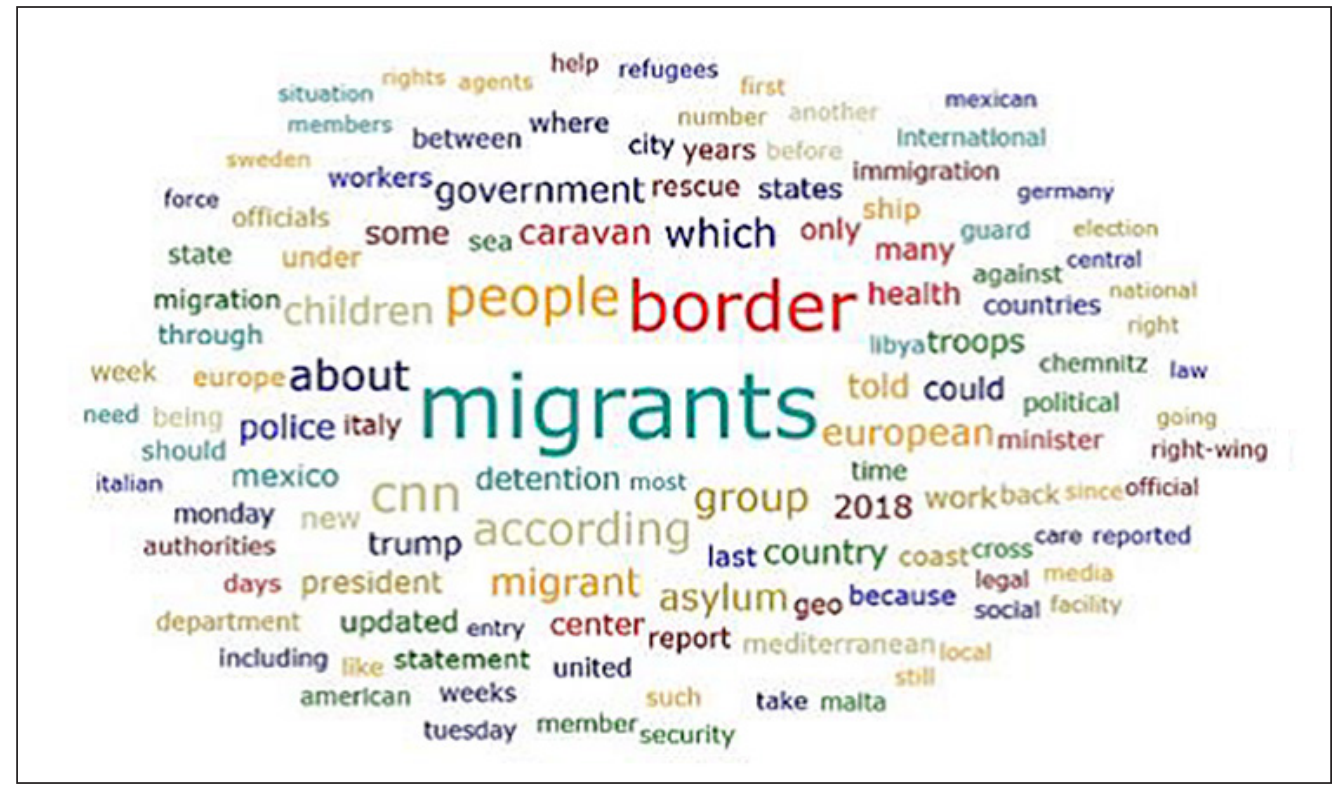

Fonte: Elaborado pelas autoras, 2018.

A observação atenta das nuvens revela que determinados termos ganham diferentes proporções e destaque: enquanto em uma nuvem são centrais na seguinte aparecem de forma bastante marginal. São exemplos disso os termos refugees e border. Significa dizer que a frequência com que foram utilizados na redação das notícias é bastante distinta.

Nesse sentido, as nuvens são um importante recurso visual para a observação das diferentes abordagens dadas pelos meios de comunicação. Logo, nota-se que a CNN usa maior quantidade de palavras para compor suas matérias. O termo migrant está destacado em ambas, uma vez que se trata do referente da análise. 
No entanto, na Figura 4, os termos border e people são sucessivamente aqueles que possuem mais menções, enquanto na Figura 3 são os termos refugees e United Nations (UN).

A separação em categorias possibilitou, ainda, observar as tendências e preferências nas abordagens do tema pelos jornais. Como demonstra a Tabela 1, ao somar a presença dos indicadores encontrados nos documentos analisados, têm-se que os aspectos de segurança, economia e tratamento são abordados mais vezes pela CNN, enquanto os direitos humanos são recorrentes na UN NEWS.

Tabela 1 - Quantidade de vezes que o aspecto foi citado

\begin{tabular}{lcc}
\hline \multicolumn{1}{c}{ Aspecto } & $\begin{array}{c}\text { UN } \\
\text { Totais }\end{array}$ & CNN \\
& 96 & Totais \\
\hline Direitos Humanos & 12 & 63 \\
Economia & 35 & 36 \\
Segurança & 34 & 75 \\
Tratamento & & 60 \\
\hline
\end{tabular}

Fonte: Elaborado pelas autoras, 2018.

A preferência por abordar um aspecto mais do que outro pode ser entendido através de Vizeu (2003), que afirma que o enquadramento dado nas matérias reflete aquilo que os jornalistas e o jornal consideram relevante. Então, a partir da tabela, pode-se inferir que a UN News confere maior importância aos direitos humanos do que a $\mathrm{CNN}$, por conseguinte, confere menor importância às pautas econômicas, de segurança e tratamento. Esses dados corroboram a hipótese de que a UN News privilegia a narrativa humanitária.

Para melhor percepção dos assuntos mais abordados pelos jornais, foi gerada a Tabela 2 que mostra a quantidade de vezes que determinado código esteve presente nos textos. Composta pelas colunas CNN, UN News e totais, ela possibilita análise mais aprofundada da utilização dos códigos. 
Tabela 2 - Número de vezes em que os códigos aparecem

\begin{tabular}{|c|c|c|c|}
\hline & $\mathrm{CNN}$ & UN NEWS & Totais \\
\hline Apoio & 56 & 63 & 119 \\
\hline Asilo & 64 & 48 & 112 \\
\hline Defesa & 14 & 0 & 14 \\
\hline descriminação & 3 & 7 & 10 \\
\hline Detenção & 42 & 26 & 68 \\
\hline Dinheiro & 17 & 8 & 25 \\
\hline Direitos Humanos & 7 & 33 & 40 \\
\hline Emprego & 8 & 2 & 10 \\
\hline Força & 5 & 0 & 5 \\
\hline Fronteira & 145 & 63 & 208 \\
\hline Medo & 15 & 1 & 16 \\
\hline Migrante & 295 & 176 & 471 \\
\hline Nacional & 25 & 18 & 43 \\
\hline oportunidade & 9 & 2 & 11 \\
\hline Proteção & 29 & 37 & 66 \\
\hline Refugiados & 23 & 132 & 155 \\
\hline Segurança & 27 & 25 & 52 \\
\hline Tropa & 44 & 0 & 44 \\
\hline Violência & 14 & 34 & 48 \\
\hline Vítima & 5 & 15 & 20 \\
\hline
\end{tabular}

Fonte: Elaborada pelas autoras, 2018.

Detendo-se aos códigos "Defesa”, "Força” e "Tropa” constata-se que eles foram empregados muitas vezes nas notícias da $\mathrm{CNN}$, remetendo à percepção da migração como ameaça. Por outro lado, nos documentos da UN News essas palavras não aparecem, o que contribui para corroborar a hipótese de uma narrativa mais humanitária por esse veículo.

Não obstante, os códigos "Violência" e "Vítima" apresentarem ocorrências na UN News, são menores do que na CNN, e se supõe que possuam ligação. Da mesma maneira, a presença dos códigos "Detenção" e "Fronteira", aludindo à imposição de barreiras e proibição de acesso, apesar de majoritariamente utilizados pela CNN, estão presentes, também, nas matérias da UN News, podendo representar sanções e segurança interna, bem como a situação dos migrantes. 
Além disso, o código "Direitos Humanos" é consideravelmente mais significativo nas notícias da UN News, a quantidade de ocorrências surpreende por ser 26 vezes superior a apresentada pela CNN. Esse resultado pode ser atribuído a importância que a ONU, como Organização, confere ao assunto, fazendo uso de seu meio de comunicação para difundi-lo.

Ainda sobre a categorização, foram criados três códigos a respeito da denominação do migrante. O intuito foi analisar a maneira como o meio de comunicação se refere a essas pessoas, diferenciando, ou não, o tipo de migração. O termo migrante alude a pessoa que busca residir em outro país, de forma permanente ou temporária, sem diferenciar migração voluntária ou refúgio (ACNUR 2016), já indivíduos que estão em busca de asilo e os refugiados passaram por migrações forçadas e têm a necessidade de ajuda.

Tabela 3 - Denominação dos migrantes

\begin{tabular}{lcc}
\hline & $\begin{array}{c}\text { UN } \\
\text { Totais }\end{array}$ & $\begin{array}{c}\text { CNN } \\
\text { Totais }\end{array}$ \\
\hline Asilo & 48 & 56 \\
Migrante & 176 & 274 \\
Refugiados & 132 & 18 \\
\hline
\end{tabular}

Fonte: Elaborado pelas autoras, 2018.

As matérias veiculadas pela CNN apresentam pouca diversidade entre as formas de denominação. Logo, foi o meio de comunicação que mais utilizou o termo migrante. Já as notícias veiculadas pela UN News utilizam mais frequentemente o termo refugiado, o que denota a diferenciação entre a circunstância da migração e a motivação dos indivíduos.

O termo migrante é, em geral, associado a questões econômicas, pobreza e emprego, enquanto refugiado remete a conflitos, perseguição e violência. Diferenciá-los é uma forma de distinguir suas necessidades e tratamentos. Em suas colocações, ao atribuir o título de migrante, a CNN não atenta para as circunstâncias que levaram esses indivíduos a migrar, suas trajetórias, locais de origem e anseios. Importante frisar que as normas internacionais a respeito de refúgio diferem das que tratam de migração.

Tendo em vista que os meios de comunicação são formadores da opinião pública, pelos quais Estados e instituições se comunicam com o público (Garrido 2014) a utilização ou supressão de determinados termos como refugiados pode 
significar a divulgação de um valor ou modelo social que se deseja inserir na sociedade.

Partindo dessa premissa, pode-se analisar a Tabela 4, que apresenta a quantidade de vezes que o país, nesse caso Estados Unidos, onde está localizada a sede do jornal CNN, foi citado nos textos, em paralelo com a utilização do nome ONU, responsável pelo portal UN News.

Tabela 4 - Número de vezes que o país ou Organização foi citado

\begin{tabular}{lccc}
\hline & CNN & UN NEWS & Totais \\
\hline EUA & 108 & 16 & 124 \\
ONU & 19 & 281 & 300 \\
\hline
\end{tabular}

Fonte: Elaborado pelas autoras, 2018.

Considerando que a presença dos códigos nos documentos representa, para além do número de citações, também o posicionamento do país ou da Organização, é plausível inferir que os jornais apresentam determinados enfoques em correspondência com os atores a quem estão atrelados. Sendo assim, a postura humanitária da UN News pode ser explicada pelo desejo da ONU em promover valores de diplomacia e cooperação, enquanto a postura econômica e securitizada da CNN reflete a relação que os EUA possuem com a temática.

\section{Considerações finais}

O estudo ora apresentado foi erigido a partir do arcabouço teórico do construtivismo, o qual entende a realidade como uma construção, em que a ação humana é criadora e criatura (Adler 1999). O sistema internacional é formado pela interação entre os atores, entre eles, a mídia. Outrossim, considerou-se a utilização da mídia como um instrumento de poder, por meio do qual os Estados e instituições disseminam seus valores (Nye 2014). Nesse sentido, as notícias foram entendidas como influenciadas por interesses, com intuito de moldar a realidade (Vizeu 2003).

Em posse desse referencial planteou-se a hipótese de que a narrativa da central de notícias da ONU, UN News, teria um caráter mais humanitário, quando comparada ao jornal CNN. Com o emprego da técnica de análise de conteúdo corroborou-se a suposição inicial. 
A UN News, ao relatar os fatos está, majoritariamente, atenta aos aspectos relacionados aos direitos humanos. Em contrapartida, a narrativa da CNN possui como principais eixos a segurança e a economia, evocando, frequentemente, o sentimento de segurança interna. Contudo, esse achado não permite afirmar que as notícias veiculadas pela CNN não se preocupam com os aspectos humanitários, apenas que os termos relacionados aos direitos humanos não são prioritários para o referido veículo, por isso recebem menor destaque e são menos frequentes do que na UN News.

Outrossim, ao passo que a CNN é uma grande corporação privada e marca licenciada, enquanto a UN News é o meio de comunicação da ONU, organização da sociedade civil sem fins lucrativos, essa linha argumentativa poderia ser uma das explicações plausíveis para a primeira apresentar maior diversidade de abordagens e léxico mais amplo. Afinal, isso aumentaria o conjunto de leitores atraídos pelas matérias e, consequentemente, seu retorno financeiro.

Paralelamente, pode-se, ainda, tratar a escolha de ênfases realizada pela CNN como representação dos interesses de seu país sede, os Estados Unidos. A agenda do governo norte-americano, bastante preocupada com aspectos securitários e econômicos, estaria impactando e sendo impactada por aquilo que é veiculado na mídia nacional.

Por fim, o motor da ciência é o acúmulo de conhecimento e o estudo de um objeto único é capaz de gerar inúmeras interpretações e diversas outras questões. Aliado a vastidão do campo a ser explorado, no que tange às temáticas, os veículos de comunicação e os recortes temporais possíveis, e tendo em vista a carência de estudos na área com aspirações empíricas, estimulamos a replicação de nossos achados, para o que disponibilizamos em anexo (anexo 1) as matérias selecionadas em nossa análise, bem como novas abordagens do tema.

\section{Referências}

ACNUR (Brasil). 2016. "Refugiados" e "Migrantes": Perguntas Frequentes. Disponível em: < http://www.acnur.org/portugues/2016/03/22/refugiados-e-migrantes-perguntasfrequentes/ > . Acesso em: 01 nov. 2018.

Adler, Emanuel. 1999. O construtivismo no estudo das relações internacionais. Lua Nova, São Paulo, n. 47, p. 201-252.

Adler, Emanuel e Michael Barnett. 1996. Governing Anarchy: a research agenda for the study of security communities. Ethics and International Affairs, v. 10, p. 63-98. 
Araújo, Bruno Bernardo. 2012. A narrativa jornalística e a construção do real, BOCC - Biblioteca Online de Ciências da Comunicação da Universidade da Beira Interior, download em: < http://www.bocc.ubi.pt/pag/araujo-bruno-a-narrativajornalistica-construcao-real.pdf $>$.

Bale, Tim. 2008. European Politics. 2.ed. New York: Palgrave, Macmillan.

Bardin, Laurence. 2016. Análise de Conteúdo. Tradução: Luís Augusto Pinheiro. Edições 70, São Paulo.

Bertonha, João Fábio. 2009. Hard, soft ou smart Power? Perspectivas para a nova política externa dos Estados Unidos. Meridiano 47, Brasília, v. 10, n. 104, p. 16-18.

Burity, Caroline Rangel Travassos. 2013. A influência da mídia nas relações internacionais: um estudo teórico a partir do conceito de diplomacia midiática. Contemporânea, v. 11, n. 1, p. 166-179.

Câmara, Rosana Hoffman. 2013. Análise de conteúdo: da teoria à prática em pesquisas sociais aplicadas às organizações. Gerais, v. 2, n. 6, p. 179-191.

Camargo, Julia Faria. 2009. Mídia e Relações Internacionais: lições da invasão do Iraque em 2003. Curitiba: Juruá.

Charaudeau, Patrick. 2006. Discurso das mídias. São Paulo: Contexto.

Costa, Marli M. Moraes e Patrícia Thomas Reusch. 2016. Migrações internacionais (Soberania, Direitos Humanos e Cidadania). Passagens, v. 8, n. 2, p. 275-292.

Defleur, Melvin L. e Sandra Bale-Rokeach. 1989. Theories of mass communication. 5. ed. Nova York: Longman Publishing. 368p.

Fierke, Karin M. e Erik Jorgensen. 2001. Constructing International Relations: The Next Generation. New York: M. E. Sharpe.

Fraga, Emerson Charlley da Fonseca. 2013. Disputa simbólica pelo poder político a construção narrativa do jornalismo. 92 f. TCC (Graduação) - Curso de Jornalismo, Departamento de Jornalismo, Universidade de Brasília, Brasília.

Gadini, Sérgio Luiz. 2007. Em busca de uma teoria construcionista do jornalismo contemporâneo. Famecos, v. 14, n. 33, p. 79-88.

Garrido, Aleksandro Palomo. 2014. El poder blando en la globalización: algunos aspectos de la comunicación en el sistema internacional. Panorama, v.8, n. 15, p. 102-115.

Gomes, Aureo. 2011. Análise do Discurso e Relações Internacionais: duas abordagens. Política Hoje, v. 20, n. 2, p. 642-676.

National Geographic. 2005. Human Migration Guide. Disponível em: < http://www. nationalgeographic.com/xpeditions/lessons/09/g68/migrationguidestudent.pd > .

Jackson, Robert e Georg Sørensen. 2018. Introdução às Relações Internacionais. Teorias e Abordagens. 3. ed. Rio de Janeiro: Zahar, 480 p.

Jesus, Diego Santos Vieira de. 2015. O mundo na primeira página: mídia, política externa e diplomacia. Comunicação \& Sociedade, v. 37, n. 2, p. 131-157. 
Kratochwil, Friedrich. 1989. Rules, Norms, and Decisions. Cambridge: Cambridge University Press.

Mcquail, Denis. 2003. Teoria da comunicação de massas. 4. ed. Lisboa: Fundação Calouste Gulbenkian. 558 p. Tradução de Carlos de Jesus.

Minayo, Maria Cecília. 2001. Pesquisa Social: teoria, método e criatividade. Petrópolis: Vozes.

Monteiro, Luís. 2001. A internet como meio de comunicação: possibilidades e limitações. In: INTERCOM XXIV Congresso Brasileiro da Comunicação, Campo Grande. Anais... Campo Grande: [s.n.], 2001. p. 27-37. Disponível em: < http://www.portcom. intercom.org.br/pdfs/62100555399949223325534481085941280573.pdf > . Acesso em: 23 ago. 2018.

Mozzato, Anelise Rebelato e Denize Grzybovski. 2011. Análise de Conteúdo como Técnica de Análise de Dados Qualitativos no Campo da Administração: Potencial e Desafios. Anpad, v. 15, n. 4, p. 731-747.

Nogueira, João Pontes e Nizar Messari. 2005. Teoria das Relações Internacionais: Correntes e Debates. Rio de Janeiro: Elsevier. 264 p.

Nogueira, Silvia. 2012. Reflexões sobre o papel da mídia na construção do nationess: os casos da Telesur e da Al-Jazeera. Carta Internacional, v. 7, n. 2, p. 117-126.

Nogueira, Silvia. 2014. A violência, o campo midiático e a construção social de uma cultura de Direitos Humanos. Revista Dat@venia, v. 6, n. 1, p. 05-19.

Nye, Joseph S. 1990. Soft Power. Foreign Policy, n. 80, p. 153-171.

Nye, Joseph S. 2004. Wielding Soft Power. In: Joseph S. Nye. Soft Power: The Means to Success in World Politics. New York: Publicaffairs, Cap. 4. p. 1-28.

Nye, Joseph S. 2014. The Information Revolution and Soft Power. Current History, v. 113, n. 759, p.19-22.

Onuf, Nicholas. 1989. World of our making: rules and rule in Social Theory and International Relations. Columbia: University of South Carolina Press.

Pereira Jr, Alfredo e Heitor C. Lima da Rocha. 2011. Jornalismo construtivista: algumas considerações epistemológicas. Famecos, v. 18, n. 3, p. 746-764.

Pinto, Danielle Jacon Ayres e Riva S. de Freitas. 2012. Política Externa e Smart Power: uma análise a partir da visão de democracia, agência e Estado de Guillermo O’Donnell. Unoesc International Legal Seminar, Chapecó, v. 1, n. 1, p. 225-240.

Rodella, Cibele A. 2005. Internet: um novo paradigma de informação e comunicação. Comunicação \& Educação, v. 10, n. 1, p. 41-48.

Souza, José Carlos Aronchi de. 2005. Seja o primeiro a saber: a CNN e a globalização da informação. São Paulo: Summos Editorial, 208p.

Traquina, Nelson. 2004. Teorias do Jornalismo - porque as notícias são como são. Ed Insular: Florianópolis. 224p. 
United Nations. 1970. Manual VI: Methods of Measuring Internal Migration. Manuals On Methods Of Estimating Population, New York, n. 47, p. 1-72, 1970. Disponível em: < http://www.un.org/esa/population/pubsarchive/migration_publications/ UN_1970_Manual6.pdf > . Acesso em: 10 nov. 2018.

United Nations. 2017. International Migration Report 2017: Highlights. New York: United Nations, 38 p. Disponível em: < http://www.un.org/en/development/desa/ population/migration/publications/migrationreport/docs/MigrationReport2017_ Highlights.pdf > . Acesso em: 10 dez. 2018.

UN Desa. 2019. United Nations Department of Economic and Social Affairs. International Migrant Stock 2019. Disponível em: < https://www.un.org/en/development/desa/ population/migration/data/estimates2/estimates19.asp > . Acesso em: 27 out. 2019.

Wendt, Alexander. 1992. Anarchy is what States Make of it: The Social Construction of Power Politics. International Organization, v. 46, n. 2, p. 391-425.

Williams, Michael. 1996. The Institutions of Security. Anais da Reunião Anual da International Studies Association.

Vizeu, Alfredo. 2003. O jornalismo e as "teorias intermediárias": Cultura profissional, rotinas de trabalho, constrangimentos organizacionais e as perspectivas da Análise do discurso (AD). In: INTERCOM, 26, 2003, Belo Horizonte. Trabalho apresentado no Núcleo de Jornalismo. Belo Horizonte: Ns. p. 1-14. Disponível em: < http://www.portcom.intercom.org.br/pdfs/1815240524327732829380525067325 7682310.pdf > . Acesso em: 20 out. 2018.

\section{Anexo 1 (Análise de Conteúdo)}

Andone, Dakin. 2018. A Latina immigrant was barred from running for state office even though she's been a US citizen for a year. Cable News Network, Atlanta, 22 jul. 2018. Disponível em: < https://edition.cnn.com/2018/07/20/us/maria-palacios-georgiaelection-immigrant-trnd/index.html > . Acesso em: 30 nov. 2018.

As human caravan moves through Mexico, 'full respect' needed for national control of borders: UN chief. 2018. UN News, Nova York, 22 out. 2018. Disponível em: < https://news.un.org/en/story/2018/10/1023852 > . Acesso em: 28 nov. 2018.

As thousands flee violence in Nicaragua, UN refugee agency urges more support for countries taking them in. 2018. UN News, Nova York, 31 jul. 2018. Disponível em: < https://news.un.org/en/story/2018/07/1015982 > . Acesso em: 9 nov. 2018.

At least 2.5 million migrants were smuggled in 2016, first UN global study shows. 2018. UN News, Nova York,13 jun. 2018. Disponível em: < https://news.un.org/en/ story/2018/06/1012102 > . Acesso em: 9 nov. 2018. 
Bangladesh: Head of UN refugee agency calls on Asia-Pacific leaders to show 'solidarity' with Rohingya refugees. 2018. UN News, Nova York, 07 ago. 2018. Disponível em: < https://news.un.org/en/story/2018/08/1016522 > . Acesso em: 9 nov. 2018.

Browne, Ryan, Barbara Starr, Geneva Sands e Caroline Kelly. 2018. Trump grants new authority to troops to protect border personnel. Cable News Network, Atlanta, 21 nov. 2018. Disponível em: < https://edition.cnn.com/2018/11/20/politics/trumpauthority-border-personnel/index.html > . Acesso em: 30 nov. 2018.

Central American migrants must be protected, urge UN experts. 2018. UN News, Nova York, 28 nov. 2018.Disponível em: < https://news.un.org/en/story/2018/11/1026831 > . Acesso em: 28 nov. 2018.

Charner, Flora e Emanuella Grinberg. 2018. Mexican officials question use of force at the border. Cable News Network, Atlanta, 27 nov. 2018. Disponível em: < https://edition.cnn.com/2018/11/26/politics/mexican-officials-tear-gas-migrants/ index.html > . Acesso em: 30 nov. 2018.

Christensen, Jen e Leyla Santiago. 2018. Despite rhetoric, illness threat from migrants is minimal, experts say. Cable News Network, Atlanta, 02 nov. 2018. Disponível em: < https://edition.cnn.com/2018/11/02/health/migrant-caravan-illness/index.html > . Acesso em: 30 nov. 2018.

Congolese expelled from Angola returning to 'desperate situation': UN refugee agency. 2018. UN News, Nova York, 16 out. 2018. Disponível em: < https://news.un.org/en/ story/2018/10/1023292 > . Acesso em: 9 nov. 2018.

Cotovio, Vasco e James Masters. 2018. Spanish police clash with migrants after 800 storm Morocco border fence. Cable News Network, Atlanta, 23 ago. 2018. Disponível em: < https://edition.cnn.com/2018/07/26/europe/ceuta-migrants-morocco-spain-intl/ index.html > . Acesso em: 30 nov. 2018.

Darcy, Oliver. 2018. Trump seizes on right-wing media reports to suggest migrant caravan has been infiltrated by 'unknown Middle Easterners'. Cable News Network, Nova York, 22 out. 2018. Disponível em: < https://edition.cnn.com/2018/10/22/media/ trump-caravan-middle-easterners/index.html > . Acesso em: 30 nov. 2018.

Dewan, Angela e Rory Smith. 2018. Polls open in Sweden after heated election campaign centered on immigration. Cable News Network, Atlanta, 09 set. 2018. Disponível em: < https://edition.cnn.com/2018/09/09/europe/sweden-election-intl/index.html > . Acesso em: 30 nov. 2018.

Driver, Alice. 2018. We have nothing to fear from the migrant march. Cable News Network, Mexico, 02 nov. 2018. Disponível em: < https://edition.cnn.com/2018/11/01/opinions/ faces-of-migrant-caravan-alice-driver/index.html > . Acesso em: 30 nov. 2018. 
Elbagir, Nima, Raja Razek e James Masters. 2018. Dutch to press United Nations for more human slavery sanctions. Cable News Network, Nova York, 24 set. 2018. Disponível em: < https://edition.cnn.com/2018/09/24/africa/libya-trafficking-prosecutions-intl/ index.html > . Acesso em: 30 nov. 2018.

Embrace migrants, value their contributions, urges Lesotho Prime Minister at UN Assembly. 2018. UN News, Nova York, 28 set. 2018. Disponível em: < https://news. un.org/en/story/2018/09/1021782 > . Acesso em: 9 nov. 2018.

EU migration deal welcomed by UN agencies. 2018. UN News, Nova York, 29 jun. 2018. Disponível em: < https://news.un.org/en/story/2018/06/1013502 > Acesso em: 9 nov. 2018.

Governments urged to 'do the hard work' to better manage global migration. 2018. UN News, Nova York, 2018. Disponível em: < https://www.un.org/development/ desa/en/news/population/governments-urged-to-do-the-hard-work-to-better-manageglobal-migration.html > . Acesso em: 26 set. 2018.

Governments need to step up protection for the most vulnerable, from 'vile crime' of human trafficking: UN chief. 2018. UN News, Nova York, 30 jul. 2018. Disponível em: < https://news.un.org/en/story/2018/07/1015902 > . Acesso em: 9 nov. 2018.

Greater support needed for refugees and migrants from Venezuela - UN. 2018. UN News, Nova York, 23 ago. 2018. Disponível em: < https://news.un.org/en/story/ 2018/08/1017642 > . Acesso em: 9 nov. 2018.

Hansler, Jennifer. 2018. Southern border tensions highlight key diplomatic vacancies. Cable News Network, Atlanta, 26 nov. 2018. Disponível em: < https://edition. cnn.com/2018/11/26/politics/us-ambassador-vacancies-mexico/index.html > . Acesso em: 30 nov. 2018.

'Historic moment' for people on the move, as UN agrees first-ever Global Compact on migration. 2018. UN News, Nova York, 13 jul. 2018. Disponível em: < https://news. un.org/en/story/2018/07/1014632 > . Acesso em: 9 nov. 2018.

Humanity has 'no choice' but to unite in the face of global threats, Chadian minister underscores at UN Assembly. 2018. UN News, Nova York, 28 set. 2018. Disponível em: < https://news.un.org/en/story/2018/09/1021672 > . Acesso em: 9 nov. 2018.

Hungarian government 'fuels discrimination against migrants', say UN human rights experts. 2018. UN News, Nova York, 14 set. 2018. Disponível em: < https://news. un.org/en/story/2018/09/1018962 > . Acesso em: 9 nov. 2018.

Immense needs of migrants making perilous journey between Yemen na Horn of Africa prompts \$45 million UM migration agency appeal. 2018. UN News, Nova York, 07 ago. 2018. Disponível em: < https://news.un.org/en/story/2018/08/1016512 > Acesso em: 20 set. 2018. 
In Tanzania visit, UNHCR official stresses freedom of choice is crucial for refugee returns. 2018. UN News, Nova York, 16 ago. 2018. Disponível em: < https://news.un.org/ en/story/2018/08/1017252 > . Acesso em: 9 nov. 2018.

Kelly, Caroline. 2018. Watchdog: HHS not conducting key background check for staff at children's detention facility. Cable News Network, Atlanta, 28 nov. 2018. Disponível em: < https://edition.cnn.com/2018/11/27/politics/hhs-ig-report-background-checks/ index.html > . Acesso em: 30 nov. 2018.

Latest tragedy in the Mediterranean claims over 100 lives - UN refugee agency. 2018. UN News, Nova York, 01 jul. 2018. Disponível em: < https://news.un.org/en/ story/2018/07/1013662 > . Acesso em: 9 nov. 2018.

Libya urged to end migrant detention amid warnings over threat to Mediterranean search and rescue. 2018. UN News, Nova York, 06 jul. 2018. Disponível em: < https://news. un.org/en/story/2018/07/1014102 > . Acesso em: 9 nov. 2018.

Mackintosh, Eliza. 2018. Hungary will not be blackmailed, Prime Minister Orban tells EU. Cable News Network, Atlanta, 12 set. 2018. Disponível em: < https://edition. cnn.com/2018/09/11/europe/viktor-orban-hungary-eu-blackmail-intl/index.html > . Acesso em: 30 nov. 2018.

Major increase in Europe's refugee and migrant death rate: UNHCR. 2018. UN News, Nova York, 04 set. 2018. Disponível em: < https://news.un.org/en/story/2018/09/1018352 > . Acesso em: 9 nov. 2018.

Mckenzie, Sheena. 2018. European Parliament votes to punish Hungary for erosion of democracy. Cable News Network, Atlanta, 12 set. 2018. Disponível em: < https://edition.cnn.com/2018/09/12/europe/hungary-orban-eu-vote-intl/index. html > . Acesso em: 30 nov. 2018.

Mckenzie, Sheena. 2018. EU could give member states $\$ 7,000$ for every rescued migrant. Cable News Network, Atlanta, 24 jul. 2018. Disponível em: < https://edition.cnn. com/2018/07/24/europe/eu-rescued-migrant-payment-plans-intl/index.html > . Acesso em: 30 nov. 2018.

Mckenzie, Sheena e Livia Borghese. 2018. Rescue ships docked as hundreds of migrants die crossing Mediterranean. Cable News Network, Atlanta, 04 jul. 2018. Disponível em: https://edition.cnn.com/2018/07/03/europe/114-migrants-missing-mediterraneanintl/index.html. Acesso em: 30 nov. 2018.

Mezzofiore, Gianluca. 2018. Italy bars its own Coast Guard ship from allowing migrants to disembark. Cable News Network, Atlanta, 21 ago. 2018. Disponível em: $<$ https://edition.cnn.com/2018/08/21/europe/diciotti-italy-coast-guard-shipmigrants-standoff-intl/index.html > . Acesso em: 30 nov. 2018. 
Mezzofiore, Gianluca, Frank Andrews, Sam Bradpiece e Hilary Mcgann. 2018. Migrant ship stranded for two weeks after four countries refuse entry. Cable News Network, Atlanta, 28 jul. 2018. Disponível em: < https://edition.cnn.com/2018/07/27/europe/ tunisian-migrant-boat-stranded-intl/index.html > . Acesso em: 30 nov. 2018.

Migrant caravan: UN agency helping 'exhausted' people home. 2018. UN News, Nova York, 30 nov. 2018. Disponível em: < https://news.un.org/en/story/2018/11/1027121 > . Acesso em: 01 dez. 2018.

Nearly three million more displaced year-on-year, warns refugee agency chief, but solutions are within reach. 2018. UN News, Nova York,19 jun. 2018. Disponível em: < https://news.un.org/en/story/2018/06/1012412 > . Acesso em: 9 nov. 2018.

Ortega, Bob. 2018. Migrants describe hunger and solitary confinement at for-profit detention center. Cable News Network, Atlanta, 11 jul. 2018. Disponível em: < https://edition.cnn.com/2018/07/11/us/northwest-immigrant-detention-centergeo-group-invs/index.html > . Acesso em: 30 nov. 2018.

Ortega, Bob. 2018. Trump said military should shoot rock-throwing migrants. Officials disagree. Cable News Network, Atlanta, 03 nov. 2018. Disponível em: < https://edition.cnn.com/2018/11/02/us/officials-dismiss-shooting-rock-throwingmigrants-trump-invs/index.html > . Acesso em: 30 nov. 2018.

Over 330,000 Congolese migrants at risk after mass deportations from Angola - UN rights chief. 2018. UN News, Nova York, 26 out. 2018, Disponível em: < https://news.un.org/en/story/2018/10/1024212 > . Acesso em: 28 nov. 2018.

Regan, Helen. 2018. Children will be brought to Australia from Nauru, but they won't be allowed to stay. Cable News Network, Atlanta, 01 nov. 2018. Disponível em: < https:// edition.cnn.com/2018/11/01/australia/nauru-children-australia-intl/index.html > . Acesso em: 30 nov. 2018.

Refugees overcrowded to 'boiling point' on Greek island, warns UN agency. 2018. UN News, Nova York, 31 ago. 2018. Disponível em: < https://news.un.org/en/story/ 2018/08/1018112 > . Acesso em: 9 nov. 2018.

Safe and orderly migration is 'in everybody's interest', says senior UN official. 2018. UN News, Nova York, 12 jul. 2018. Disponível em: < https://news.un.org/en/ story/2018/07/1014581 > . Acesso em: 9 nov. 2018.

Said-Moorhouse, Lauren e Hada Messia. 2018. Salvini facing investigation as migrants in Italy finally allowed to disembark. Cable News Network, Atlanta, 26 ago. 2018. Disponível em: < https://edition.cnn.com/2018/08/26/europe/eu-italy-migrationintl/index.html > . Acesso em: 30 nov. 2018. 
Sands, Geneva e Sophie Tatum. 2018. Migrants may have to wait 6 weeks at border to claim asylum, official says. Cable News Network, Atlanta, 28 nov. 2018. Disponível em: < https://edition.cnn.com/2018/11/27/politics/migrant-caravan-processingtime/index.html > . Acesso em: 30 nov. 2018.

Schmidt, Nadine e Laura Smith-Spark. 2018. Anti-migrant protests continue for third night in Germany. Cable News Network, Alemanha, 30 ago. 2018. Disponível em: < https://edition.cnn.com/2018/08/30/europe/germany-protests-chemnitz-intl/ index.html > . Acesso em: 30 nov. 2018.

Shoichet, Catherine. 2018. Mexico walks political tightrope over migrants moving north. Cable News Network, Atlanta, 30 out. 2018. Disponível em: < https://edition.cnn.com/ 2018/10/30/americas/mexico-migrants-response/index.html > . Acesso em: 30 nov. 2018.

Shoichet, Catherine, Leyla Santiago e Geneva Sands. 2018. They're steps away from the US border. But crossing it legally could take weeks. Cable News Network, Atlanta, 15 nov. 2018. Disponível em: < https://edition.cnn.com/2018/11/15/americas/ migrants-tijuana/index.html > . Acesso em: 30 nov. 2018.

Shubert, Atika. 2018. Mob violence stuns Germany, revealing deep fault lines over migration. Cable News Network, Alemanha, 02 set. 2018. Disponível em: < https://edition.cnn.com/2018/09/01/europe/germany-chemnitz-shubert-intl/ index.html > . Acesso em: 30 nov. 2018.

Shubert, Atika e Nadine Schmidt. 2018. He went to Greece to help migrants, now he's accused of trafficking them. Cable News Network, Atlanta, 19 out. 2018. Disponível em: < https://edition.cnn.com/2018/10/19/europe/search-rescue-volunteers-prisonintl/index.html > . Acesso em: 30 nov. 2018.

Shubert, Atika, Linnéa Wannefors e Angela Dewan. 2018. Swedish election deadlock as far-right party makes gains. Cable News Network, Suécia, 10 set. 2018. Disponível em: < https://edition.cnn.com/2018/09/10/europe/sweden-elections-results-intl/ index.html > . Acesso em: 30 nov. 2018.

Smith-Spark, Laura. 2018. UK fruit farmers feel the squeeze as Brexit looms. Cable News Network, Inglaterra, 21 set. 2018. Disponível em: < https://edition.cnn.com/ 2018/09/21/uk/uk-europe-seasonal-workers-brexit-intl/index.html > . Acesso em: 30 nov. 2018.

Sparks, Grace. 2018. Majority say migrants in caravan should be given the opportunity to enter the country. Cable News Network, Atlanta, 19 nov. 2018. Disponível em: < https://edition.cnn.com/2018/11/19/politics/migrants-poll/index.html > . Acesso em: 30 nov. 2018. 
Starr, Barbara e Zachary Cohen. 2018. Texas border troops' future unclear as initial task nears completion. Cable News Network, Washington, 14 nov. 2018. Disponível em: $<$ https://edition.cnn.com/2018/11/13/politics/mattis-border-trip-us-troops/index. html > . Acesso em: 30 nov. 2018.

Two shipwrecks add to 'alarming increase' in migrant deaths off Libya coast: IOM. 2018. UN News, Nova York, 02 jul. 2018. Disponível em: < https://news.un.org/en/ story/2018/07/1013712 > . Acesso em: 9 nov. 2018.

UN agencies call for more resettlement and end to detention of asylum seekers in Libya. 2018. UN News, Nova York, 23 nov. 2018. Disponível em: < https://news.un.org/ en/story/2018/11/1026441 > . Acesso em: 28 nov. 2018.

UN chief applauds Bangladesh for 'opening borders' to Rohingya refugees in need. 2018. UN News, Nova York, 01 jul. 2018. Disponível em: < https://news.un.org/en/ story/2018/07/1013672 > . Acesso em: 9 nov. 2018.

UN agency chiefs issue 'call to action' on behalf of refugee children. 2018. UN News, Nova York, 20 jun. 2018. Disponível em: < https://news.un.org/en/story/2018/06/1012612 > . Acesso em: 9 nov. 2018.

UN chief calls for 'solidarity, compassion and action' on World Refugee Day. 2018. UN News, Nova York, 20 jun. 2018. Disponível em: < https://news.un.org/en/ story/2018/06/1012532 > . Acesso em: 9 nov. 2018.

UN mobilizes in Rohingya camps to support babies born of rape; young mothers face stigma. 2018. UN News, Nova York,19 jun. 2018. Disponível em: < https://news. un.org/en/story/2018/06/1012372 > . Acesso em: 9 nov. 2018.

UNHCR welcomes deal to end latest migrant stand-off in Mediterranean Sea. 2018. UN News, Nova York, 19 jul. 2018. Disponível em: < https://news.un.org/en/story/ 2018/07/1015102 > . Acesso em: 9 nov. 2018.

US must abide by humanitarian refugee accords: UN refugee agency. 2018. UN News, Nova York, 9 nov. 2018. Disponível em: < https://news.un.org/en/story/2018/11/1025411 > . Acesso em: 9 nov. 2018.

Vazquez, Maegan, Geneva Sands, Kevin Liptak e Sarah Westwood. 2018. White House issues new rule limiting asylum seekers. Cable News Network, Washington, 08 nov. 2018. Disponível em: < https://edition.cnn.com/2018/11/08/politics/asylum-ruletrump-migrants/index.html > . Acesso em: 30 nov. 2018.

Venezuelan exodus to Ecuador reaches record levels: UN refugee agency steps up aid. 2018. UN News, Nova York, 10 ago. 2018. Disponível em: < https://news.un.org/ en/story/2018/08/1016812 > . Acesso em: 9 nov. 2018.

Walsh, Nick Paton. 2018. Week of chaos a reminder that Libya is still broken. Cable News Network, Atlanta, 03 set. 2018. Disponível em: < https://edition.cnn.com/2018/09/03/ africa/libya-violence-analysis-intl/index.html > . Acesso em: 30 nov. 2018. 
We stopped migration with a €1billion border fence - Hungarian Minister tells General Assembly. 2018. UN News, Nova York, 28 set. 2018. Disponível em: < https://news. un.org/en/story/2018/09/1021732 > . Acesso em: 9 nov. 2018.

Yeung, Jessie. 2018. Gibraltar ship stripped of flag amid dispute over migrants stranded at sea. Cable News Network, Atlanta, 14 ago. 2018. Disponível em: < https://edition. cnn.com/2018/07/27/europe/tunisian-migrant-boat-stranded-intl/index.html > . Acesso em: 30 nov. 2018.

Yeung, Jessie. 2018. Stranded rescue ship with 141 migrants allowed to dock in Malta. Cable News Network, Atlanta, 16 ago. 2018. Disponível em: < https://edition.cnn. com/2018/08/16/europe/aquarius-disembark-malta-intl/index.html > . Acesso em: 30 nov. 2018. 